Supplement of Ocean Sci., 14, 403-415, 2018

https://doi.org/10.5194/os-14-403-2018-supplement

C Author(s) 2018. This work is distributed under

the Creative Commons Attribution 4.0 License.

(c) (1)

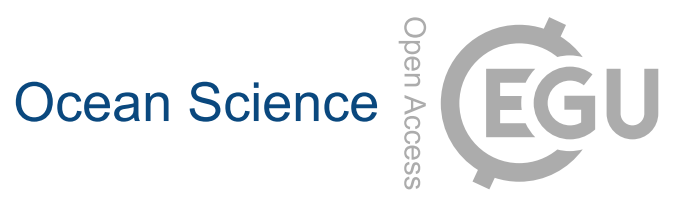

Supplement of

\title{
High-resolution diapycnal mixing map of the Alboran Sea thermocline from seismic reflection images
}

\section{Jhon F. Mojica et al.}

Correspondence to: Jhon F. Mojica (jhon.mojica@nyu.edu)

The copyright of individual parts of the supplement might differ from the CC BY 4.0 License. 

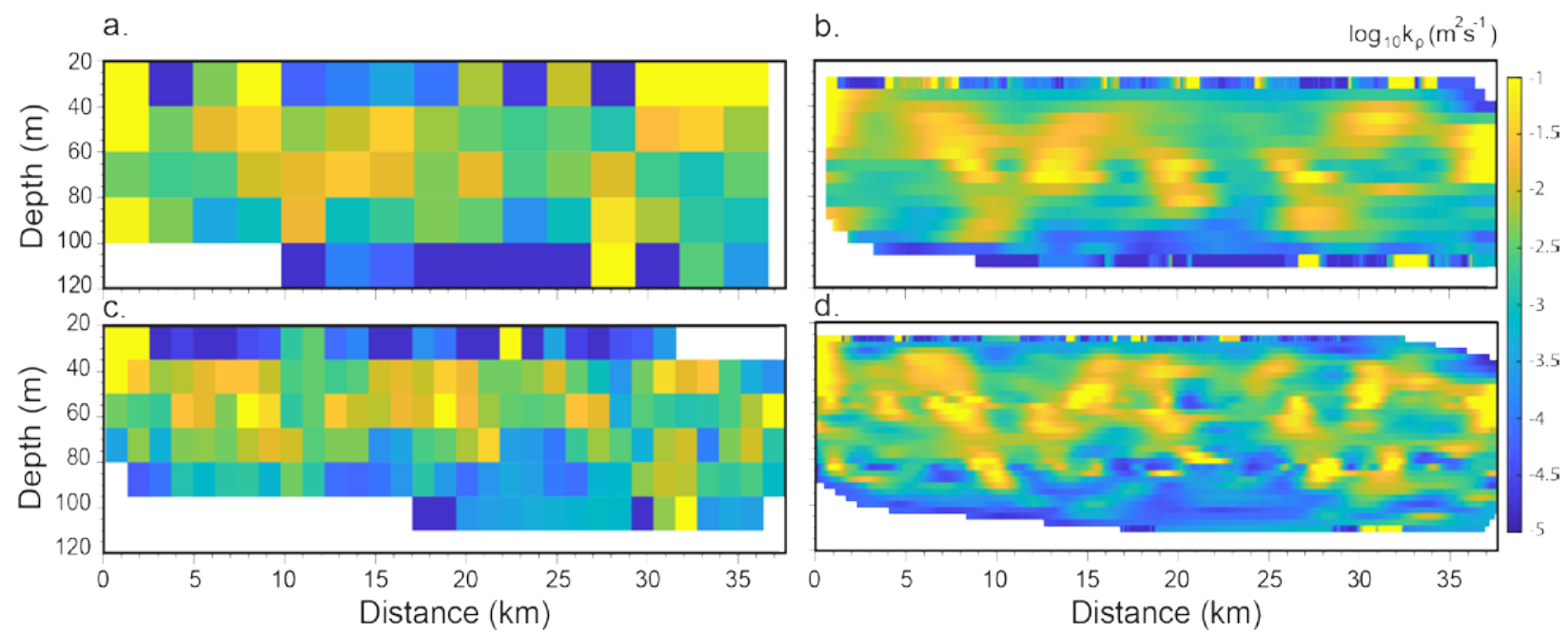

Figure S1. Four examples of $k_{\rho}(x, z)$ maps obtained along the seismic profile shown in Fig.1, using 5 windows of different size, with and without applying the sliding window approach. (a) Window size is $2400 \mathrm{~m}$ wide $\times 20 \mathrm{~m}$ high. (b) Same window size as in (a), but applying sliding window step of $60 \mathrm{~m}$ in the horizontal and $6 \mathrm{~m}$ in the vertical one, between neighboring windows. (c) Window size is $1200 \mathrm{~m}$ wide $\times 15 \mathrm{~m}$ high. (d) Same window size as in (c), but applying a sliding window step of $30 \mathrm{~m}$ (horizontal) and $3 \mathrm{~m}$ (vertical). This is the one selected and used for the analysis. 

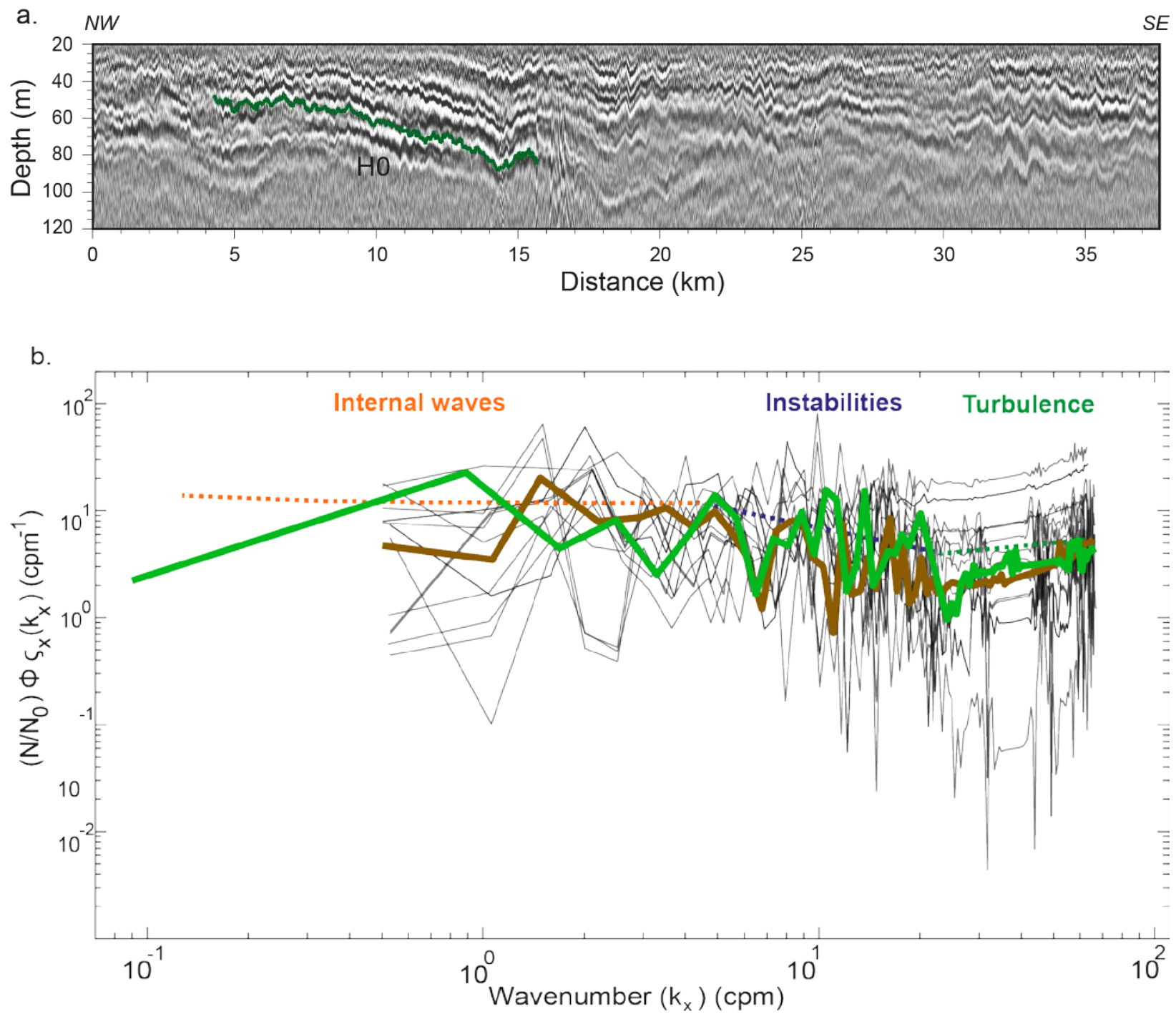

40 Figure S2 (a) Depth-converted high-resolution multichannel seismic profile (Here we show a new horizon H0, green line). (b) Horizontal spectrum of the vertical displacement of reflector H0. (green line) considering the whole reflector. (black lines) spectrum from the reflector split in ten $1.2 \mathrm{~km}$-long segments. (brown line) average spectrum from the 10 segments. Segments, the average and the whole reflector show the same trends in the scales of interest. 


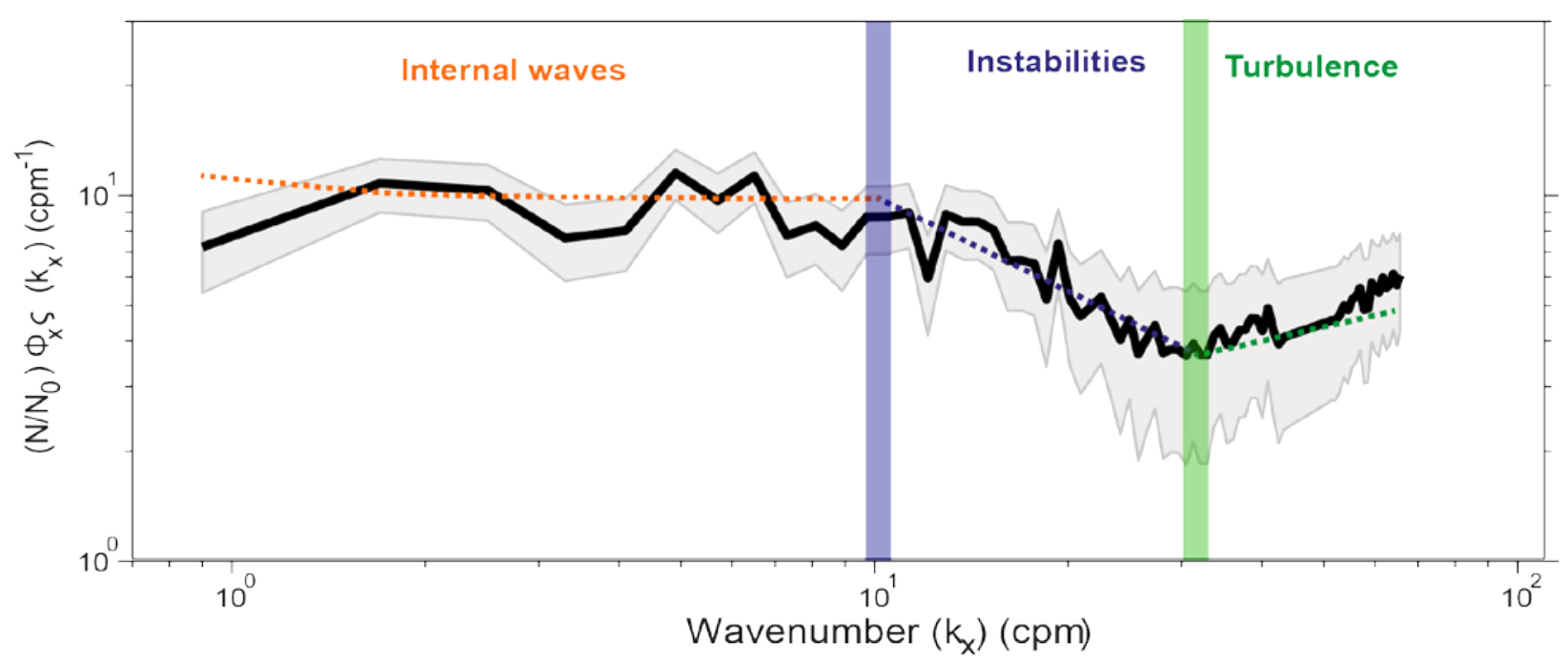

50 Figure S3. Average horizontal spectrum of the 68 tracked reflectors scaled by the local buoyancy frequency at the reflector depth, and multiplied by $\left(2 \pi k_{x}\right)^{2}$ (solid line) and its corresponding $95 \%$ confidence interval $(2 \sigma)$ (shaded area). The reference lines are the theoretical slopes corresponding to the GM79 model for the internal wave subrange (red line), Kelvin-Helmholtz instabilities for the transitional/buoyancy subrange (blue line), and Batchelor59 model for turbulence (green line).

55 The steeper slope at the highest wavenumbers corresponds to noise. The blue rectangle marks the buoyancy scale $\left(l_{N} \approx 100 \mathrm{~m}\right)$, and the green rectangle the limit between transitional and turbulent subranges $(\sim 30 \mathrm{~m})$

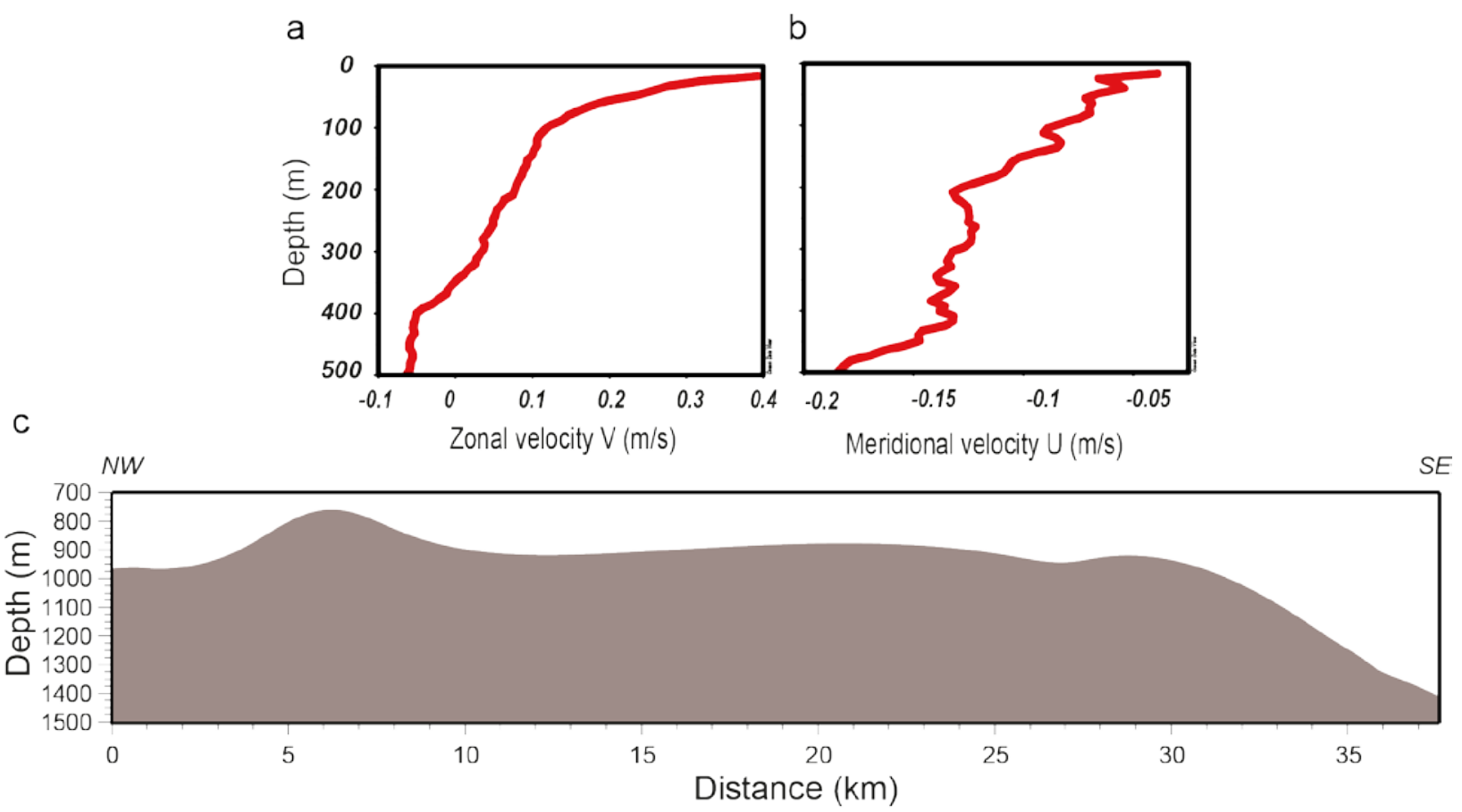

60 Figure S4. (a) Current velocity profile from ADCP data, SAGAS in May, 2010. (a) The zonal velocity $(V)$ variations, and $(b)(U)$ the meridional velocity $(U)$ variations according to the depth. (c) Bathymetric profile over the seismic profile. 